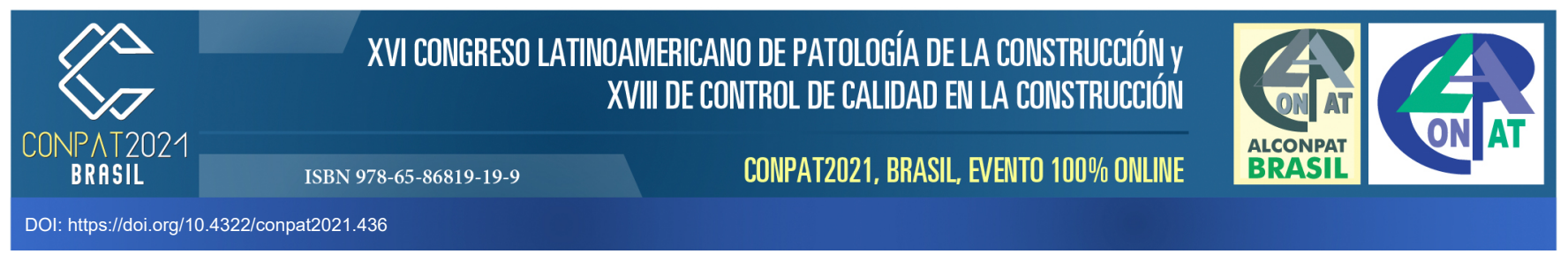

\title{
Manifestações patológicas em edifícios públicos no município de Viradouro - SP.
}

\author{
Gonçalves. G. H. V. ${ }^{1}{ }^{*}$, Rocha. L. B. G. da. ${ }^{1}$, Marques Neto. J. da C. ${ }^{1}$, Serra. S. M. B. ${ }^{1}$ \\ *Autor de Contato: gustavovital@hotmail.com.br \\ ${ }^{1}$ Programa de Pós Graduação em Engenharia Civil, Universidade Federal de São Carlos, São Carlos, Brasil
}

\begin{abstract}
RESUMO
Nota-se um aumento significativo de manifestações patológicas em edificações, sendo de suma importância identificá-las, preveni-las e tratá-las, a fim de impedir problemas estruturais graves além dos danos estéticos. Este trabalho teve como objetivo realizar um diagnóstico das manifestações patológicas em edificações. Com este propósito, desenvolveu-se um estudo de caso, pautado na análise minuciosa de manifestações patológicas em edifícios públicos do município de Viradouro -SP, contando com registros fotográficos que comprovam os levantamentos. Desse modo, obteve-se como resultado as principaiss manifestações patológicas encontradas; os motivos que as acarretaram; a relevância da impermeabilização e da qualidade dos materiais utilizados em uma construção e a falta de manutenção preventiva e corretiva em edificações públicas.
\end{abstract}

Palavras chave: Manifestações patológicas; edificações públicas; anomalias; materiais. 


\begin{abstract}
There is a significant increase in pathologies in buildings, being of paramount importance to identify, prevent and treat them, in order to prevent serious structural problems in addition to aesthetic damage. This work aimed to make a diagnosis of pathological manifestations in buildings. For this purpose, a case study was developed, based on the detailed analysis of pathological manifestations in public buildings in the municipality of Viradouro - SP, with photographic records that prove the surveys. Thus, the main pathologies found were obtained as a result; the reasons that led to them; the relevance of waterproofing and the quality of the materials used in a construction and the lack of preventive and corrective maintenance in public buildings.
\end{abstract}

Keywords: Pathology; pathological manifestations; public buildings; anomalies; materials.

\title{
RESUMEN
}

Existe un aumento significativo de patologías en los edificios, siendo de suma importancia identificarlas, prevenirlas y tratarlas, con el fin de prevenir problemas estructurales graves además de daños estéticos. Este trabajo tuvo como objetivo realizar un diagnóstico de manifestaciones patológicas en edificaciones. Para ello, se desarrolló un estudio de caso, basado en el análisis detallado de manifestaciones patológicas en edificios públicos del municipio de Viradouro - SP, con registros fotográficos que acreditan las encuestas. Así, se obtuvieron como resultado las principales patologías encontradas; las razones que los llevaron; la relevancia de la impermeabilización y la calidad de los materiales utilizados en una construcción y la falta de mantenimiento preventivo y correctivo en los edificios públicos.

Palabras llave: Patología; manifestaciones patológicas; edificios públicos; anomalías materiales.

\section{INTRODUÇÃO}

Com o crescimento do setor da construção civil foi inevitável a adaptação de novos materiais e novas tecnologias para evitar o surgimento de novas manifestações patológicas, porém é importante salientar que os materiais em si não são os causadores de novas anomalias, e sim a falta de mão de obra qualificada e o desconhecimento do emprego correto destas inovações, além da falta de manutenção preventiva (LIMA, 2015).

A execução de edificações de alta durabilidade é prioridade, sendo alcançada, especialmente, por meio da introdução de novos materiais, projetos e contratação especializada de colaboradores. No entanto, equívocos podem ser cometidos em diferentes estágios da construção, ocasionando problemas patológicos e comprometimento do desempenho das edificações até mesmo na fase inicial de sua ocupação (CAPORRINO, 2015).

A ocorrência de manifestações patológicas em edificações está ligada às falhas construtivas, de projeto e em sobrecargas na estrutura. Contudo, é importante ressaltar que as manifestações patológicas se manifestam em todos os tipos de estruturas, sendo elas antigas ou novas e bem projetadas (GONÇALVES, 2015).

É significativo considerar, no entanto, que o edifício e suas partes reagem com o meio e em função das condições de exposição a que estão submetidos sofrem uma série de fenômenos físicos, químicos e biológicos que podem provocar a queda de desempenho. Essa interação pode vir a se tornar sintomas e a situação tende a se agravar com o decorrer do tempo (VALLE, 2008). 
Ao analisar um imóvel é de suma importância compreender o motivo do aparecimento e desenvolvimento da manifestação patológica em questão, sempre buscando o esclarecimento das causas antes das prescrições e, consequentemente, aplicação das correções, com o intuito de eliminar o problema identificado (SOUZA; RIPPER, 1998).

A falta de manutenção preventiva acaba contribuindo para o surgimento de anomalias que acarretam graves problemas estéticos ou estruturais e, por conseguinte, elevados gastos na tentativa de reparar a estrutura ou, em casos mais extremos, a condenação da edificação sendo necessário a demolição (BAUER, 2000).

Essa falta de manutenção está muito presente em prédios públicos. Visto que é frequente nos municípios brasileiros se deparar com edifícios utilizados para prestação de serviços para a população, tais como: creches, escolas, hospitais, postos de saúde, em situação precária, má conservação, pouca iluminação com infraestrutura debilitada, e diante de situações como essas, os próprios funcionários solucionam provisoriamente os problemas, por meio de "consertos" com materiais inadequados (GALVÃO, JOSÉ E GOMES, 2017).

Segundo a ABNT NBR 5674:2012 o órgão ou setor público responsável pela edificação, consequentemente está encarregado da manutenção da mesma, sendo seu dever acatar o que está determinado nas normas técnicas e no manual de operação, uso e manutenção, podendo conceder a gestão da manutenção para empresa ou profissional legalmente habilitado (ABNT, 2012).

Diante do exposto, este trabalho tem por objetivo realizar o levantamento das manifestações patológicas encontradas nos prédios públicos no município de Viradouro - SP, além de propor soluções para reparar tais anomalias.

\section{METODOLOGIA}

O desenvolvimento deste trabalho caracteriza-se como um estudo de caso. Segundo CAMPOMAR (1991), o estudo de caso se enquadra em uma tipologia de pesquisa pautada em análise minuciosa, possibilitando examinar um ambiente e levantar dados.

Foram realizadas vistorias em cinco edificações públicas do município de Viradouro-SP no ano de 2020. As edificações escolhidas foram as que apresentaram maior número de anomalias e de maior gravidade.

A coleta de dados foi feita através de inspeção visual desses prédios. Não foram utilizados equipamentos físicos ou químicos para análise das anomalias.Foram registrados em planilhas os dados observados para posterior refinamento e análise dos resultados.

Durante a vistoria, fez-se uma lista dos principais problemas encontrados, buscando por meio de conversas com funcionários da prefeitura, como engenheiro, arquiteita, colaboradores que trabalham nos prédios analisados, para entender as possíveis

causas das manifestações patológicas. Após o entendimento das causas passa-se a analisar quais seriam as melhores soluções de reparo, elaborando-se uma proposta na qual geralmente consta uma ou duas opções de reparo, buscando nessas soluções considerar duas questões primordiais: durabilidade e custo (não será abordada neste artigo a questão relativa às soluções de reparo).

Foi utilizado nas vistorias, um questionário realizado a partir do check-list da ABECE (2005) para adquirir dados que reforçam o que foi observado e analisado in loco. Houve a realização de pesquisas através de bibliografias especializadas com obtenção de dados fundamentais para esta pesquisa com a finalidade de embasar o estudo.

\section{RESULTADOS E DISCUSSÃO}

Através da análise realizada in loco, constatou-se diversas manifestações patológicas nos edifícios públicos do município de Viradouro - SP, que foram identificadas com base no levantamento do referencial teórico deste trabalho. 


\subsection{Estudo de Caso 1}

O descolamento de placas é uma patologia frequente em edificações. Na Figura 1, identifica-se uma deterioração do reboco devido à infiltração, observado no salão de festas denominado centro comunitário que se localiza na Av Manoel Inocêncio no município de Viradouro. Logo, observase na imagem o descolamento parcial do revestimento e, na parte superior da edificação, marcas de mofo.

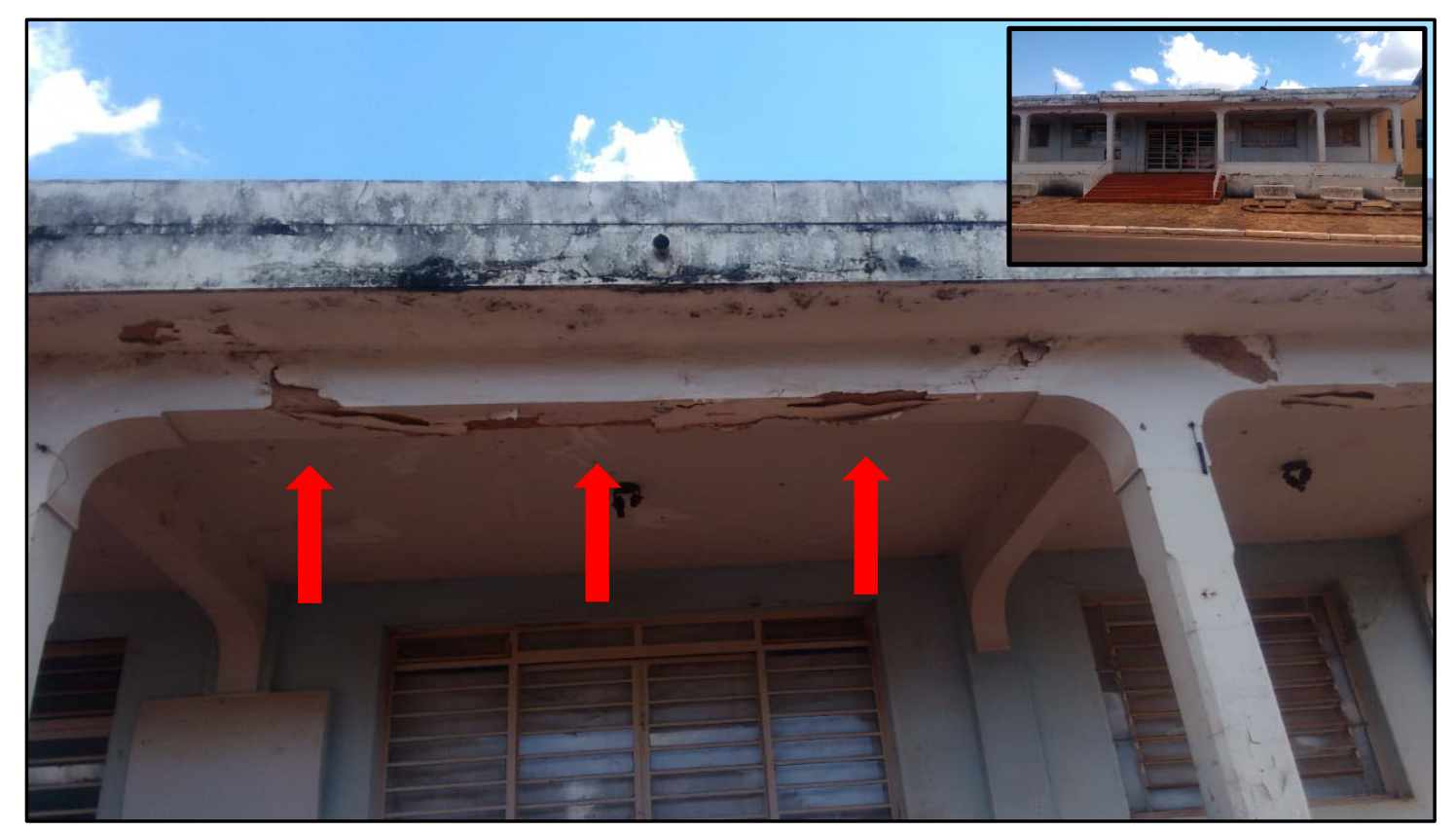

Figura1. Deterioração do reboco devido a infiltração - Centro Comunitário, salão de festas de Viradouro/SP.

Quando as camadas do revestimento argamassado desprendem-se uma da outra, recebe-se o nome de descolamento. O revestimento tem por finalidade a proteção, segurança e conforto de uma edificação, o surgimento de descolamentos é bem mais que um problema estético (nota-se na figura o quão danificado está a estética do prédio em questão, dando impressão de abandono).

Durante a execução do projeto, falhas podem acarretar descolamentos futuros, tais como: escolhas de materiais inadequados, ou seja, incompatíveis com as condições de uso ou falhas técnicas. Essa patologia pode ser ocasionada por fatores externos, como por exemplo a umidade, conforme constatado na figura 1, observe a presença de manchas de bolor e mofo que constatam a umidade presente no local.

Descolamentos são considerados graves, visto que podem causar acidentes e os custos de reparo são altos, pois a renovação do revestimento é necessária. Assim como as demais manifestações patológicas, estes podem ser evitados, por meio de elaboração de projetos detalhados, controle dos materiais, mão de obra qualificada.

Conforme Arivabene (2015), a umidade é uma das anomalias mais recorrentes em edificações. Pode causar sérias consequências à estrutura de uma construção, como vazamentos, infiltrações, manchas e eflorescencia, e representa um dos problemas mais difíceis de serem corrigidos dentro da construção civil. Essa dificuldade está relacionada à complexidade dos fenômenos envolvidos e à falta de estudos e pesquisas.

O caso 1 apresenta descolamento com pulverulência, sendo perceptível a desagregação e o esfarelamento da argamassa, até mesmo quando pressionadas manualmente (ato realizado ao 
examinar a edificação). Atente que além da argamassa, também há descolamento da película da tinta, o que caracteriza o descolamento mencionado.

Como terapia para a anomalia identificada cita-se a reiteração do revestimento com apicoamento da base, remoção da base hidrófuga e reaplicação do chapisco. É fundamental nesse caso que haja a eliminação da infiltração, após a remoção do revestimento, acrescentando um impermeabilizante e repondo um outro revestimento.

\subsection{Estudo de Caso 2}

O caso 2 representa uma situação comumente em prédios e residências. Conforme observado na imagem a seguir, a presença de bolor e mofo é visível na fachada da Prefeitua Municipal localizada na Praça Major Manoel Joaquim, 349 Viradouro SP. Nesse caso, a anomalia é excesso de umidade por se tratar de uma área externa, ocasionado quando a água da chuva penetra pela fachada como mostra a Figura 2.

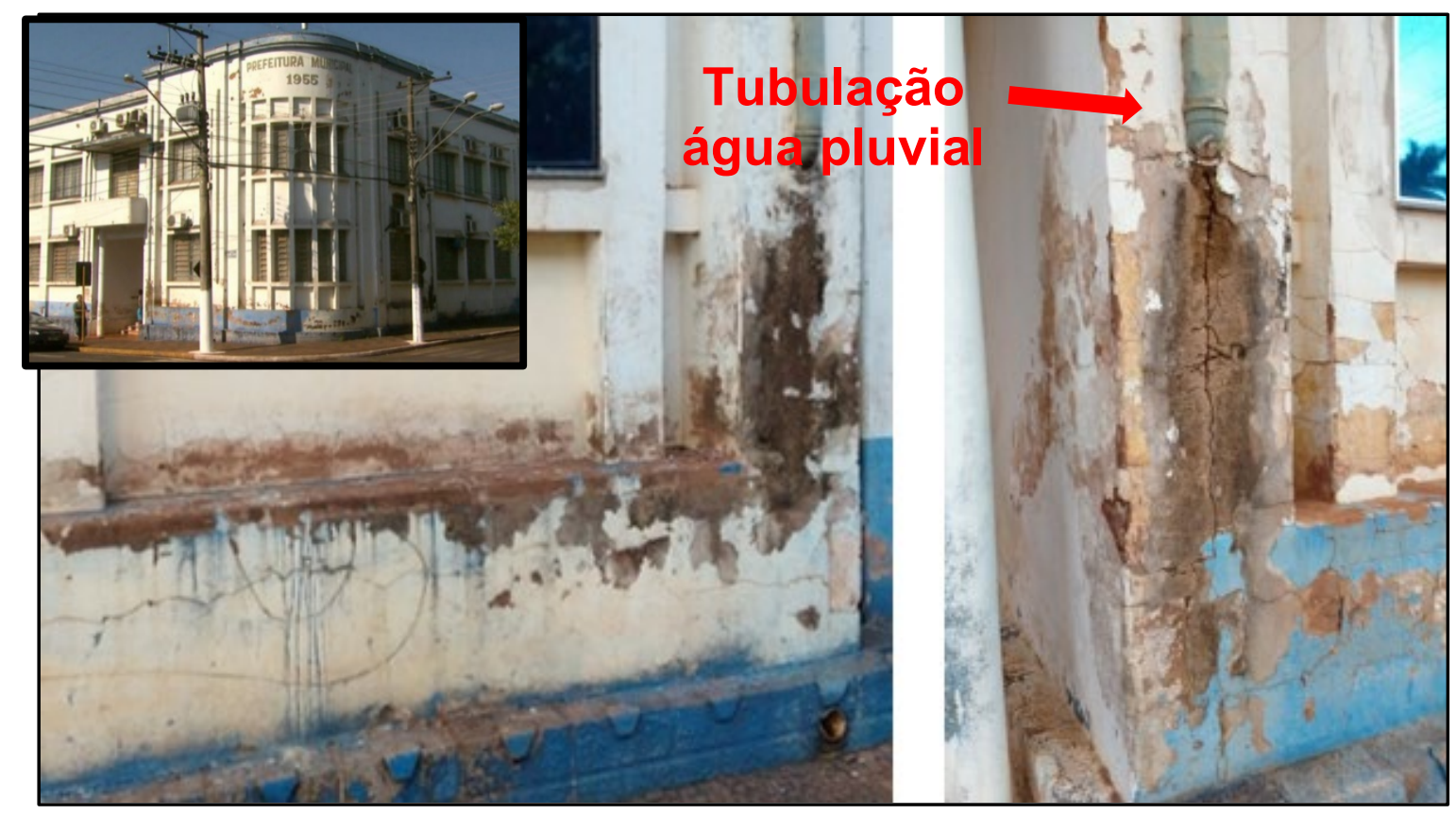

Figura 2. Manchas de bolor e mofo - Prefeitura Municipal de Viradouro/SP

O excesso de umidade pode causar vários transtornos. Para edificações, pode danificar a estrutura e o revestimento do imóvel. Já para saúde dos moradores pode causar doenças respiratórias, alergias devido aparecimento de bolores e mofos. Na fachada, raramente ocorre por causa da permeabilidade dos materiais usados, mas sim pela ocorrência de fisuras (CINCOTTO, 1988).

Possíveis terapias para o problema: blocos de baixa movimentação interna, o que evitaria fissuras; projetar beirais, ressaltos ou molduras, impedindo a formação da lâmina de água; lavagem com solução de hipoclorito de sódio e aplicação de protetores de fachada (hidrofugante), troca de revestimento (argamassa).

\subsection{Estudo de Caso 3}

Fissura vertical por retração na alvenaria em ponto enfraquecido por tubulação embutida, encontrada em uma das dependências do Hospital e Maternidade São Vicente de Paula localizado na Rua do Hospital em Viradouro SP, conforme mostra a Figura 3. 


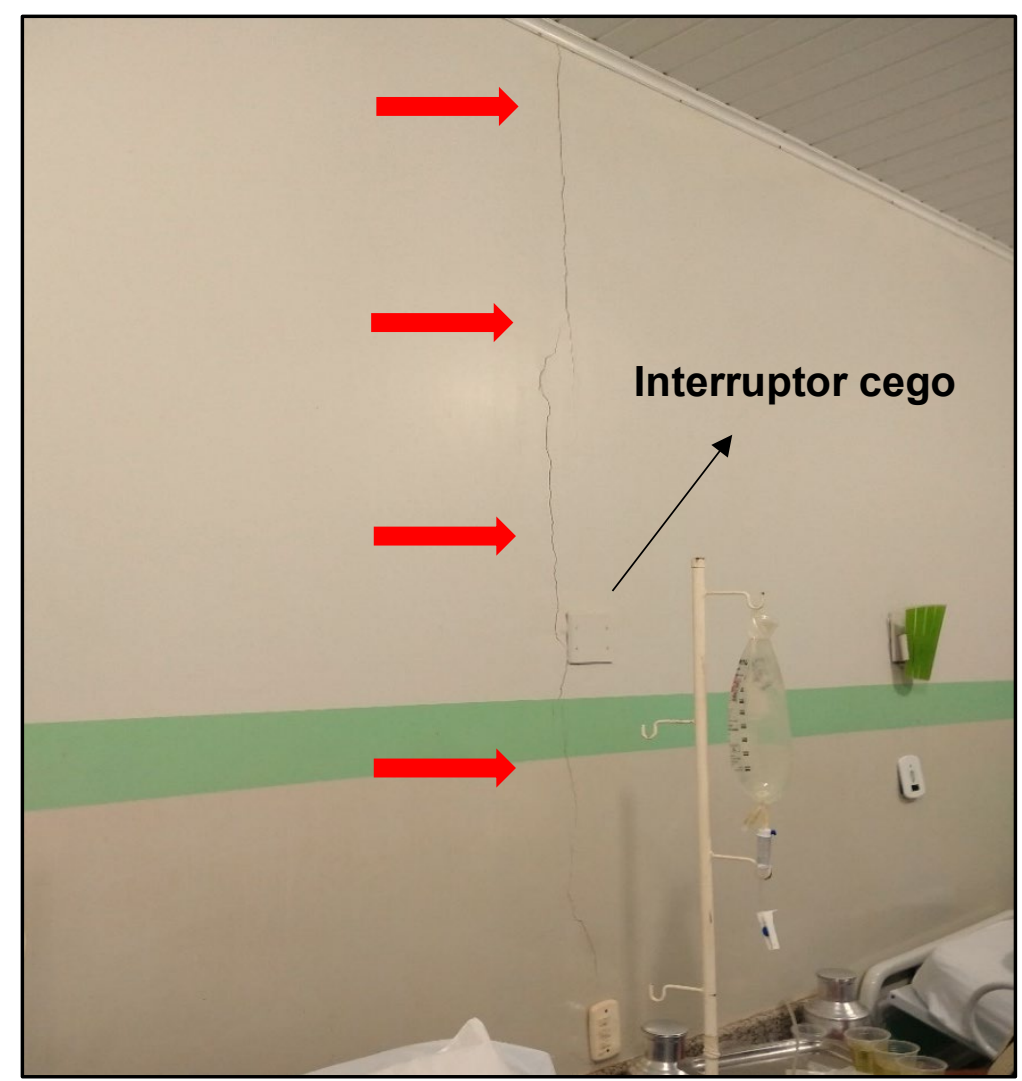

Figura 3. Fissura vertical de retração em alvenaria - Hospital e Maternidade São Vicente de Paula Viradouro/SP.

relacionados a exposição e deterioração da armadura. Mesmo não sendo estruturais acabam impactando negativamente na vida útil das estruturas, mesmo não condenando diretamente a estrutura, elas acabam facilitando a entrada de agentes oxidantes como água e oxigênio (Helene, 2003).

A retração das argamassas é determinante para o aparecimento e desenvolvimento de trincas e fissuras, além de destacamentos nas regiões de ligação com componentes estruturais. As fissuras poderão ocorrer nos encontros entre paredes, no terço médio de paredes muito extensas ou mesmo em seções enfraquecidas pela presença de eletrodutos ou tubulações hidráulicas e hidro sanitárias. Há vários modos de tratar esse tipo de fissura, dentre elas: aplicação de microcimento; fluorsilicato; nata de cimento ou tela adesiva de poliéster para reparo de fissuras a fim de fechar superficialmente as mesmas. É imprescindível efetuar a limpeza do local retirando a poeira, grãos de areia e partículas soltas das fissuras, empregando-se jato de ar limpo.

Fissuras e manchas são um sinal que a estrutura apresenta quando está sendo afetada por problemas

\subsection{Estudo de Caso 4}

O caso 4 apresenta corrosão em armaduras de concreto armado encontrada em duas edificações públicas. Na figura 4(a) ocorre corrosão em uma das vigotas da laje, nota-se a presença de umidade no local e o desprendimento do revestimento argamassado. Já na figura 4 (b) observa-se o descolamento do revestimento por consequência de algum impacto, e com isso fica exposta parte da armadura do pilar na fachada da edificação, podendo haver contato direto com água da chuva. 


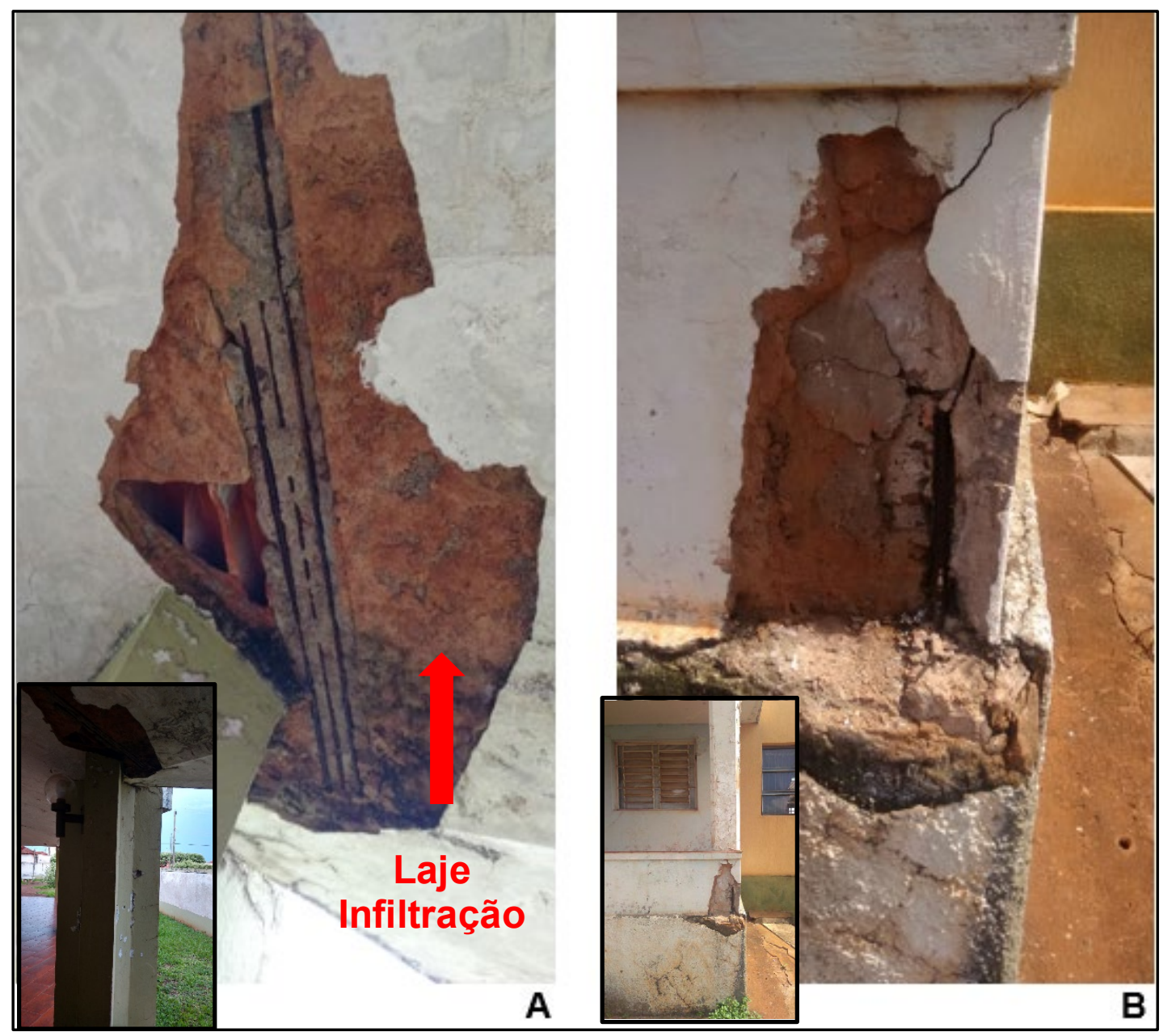

Figura 4. Corrosão em armaduras de concreto armado - Velório Municipal e Centro Comunitário Viradouro/SP.

A corrosão consiste na degradação dos materiais metálicos, ocorre quando uma película de eletrólito se forma sobre a superfície dos fios ou barras de aço, esta é causada pela presença de umidade no concreto e gera perda de seção.

A figura 4, tanto prédio (a) quanto (b) exemplifica uma corrosão eletroquímica, também conhecida como corrosão em meio aquoso, em virtude da presença de água na estrutura, ocorre, normalmente, à temperatura ambiente, é caracterizada pela transferência de elétrons, ou seja, formação de uma pilha ou célula de corrosão, havendo a circulação de elétrons na superfície metálica. Esse é o tipo mais comum de corrosão.

A corrosão eletroquímica envolve reações de oxirredução. Este tipo de reação acontece com a transferência de elétrons, esta pode ocorrer espontaneamente ou não. No caso da corrosão citada, as reações de oxirredução são todas espontâneas.

A pilha de corrosão é caracterizada pela ocorrência de reação de oxidação e redução juntas, porém para que isso ocorra, quatro elementos precisam existir: área anódica, onde ocorre a oxidação; área catódica, onde ocorre a redução; eletrólito, solução condutora de elétrons que cobre as áreas anódicas e catódicas simultaneamente e ligação elétrica entre as duas áreas. A área anódica corresponde à corrosão do aço, notória pela ferrugem, facilmente identificada na figura. A área catódica consiste na parte protegida do aço, onde não ocorre corrosão. O eletrólito é a água 
encontrada na natureza contendo sais, ácidos ou bases, como por exemplo, cloretos, sulfatos e sulfetos. E a ligação elétrica é a própria peça.

A corrosão eletroquímica está presente em basicamente todos os locais onde identifica-se ferrugem. Para que a corrosão seja evitada, basta eliminar um dos quatro elementos essenciais para a formação da pilha, por se tratar de elementos naturais, será necessária a intervenção humana, através de uso de materiais especiais, mais resistentes à corrosão, como por exemplo, o aço inoxidável; aplicar barreiras por meio de pinturas com tintas desenvolvidas como película de proteção; utilização de métodos de proteção catódica ou anódica, um exemplo seria a aplicação de placas de zinco, porém exige manutenção, visto que o zinco necessita ser reposto.

Helene (2003) observa que, no Brasil, a manifestação patológica que mais preocupa é a corrosão de armaduras, pois se trata do processo mais agressivo aos vergalhões, ele gera ferrugem nas barras e consequentemente alteram sua seção comprometendo sua resistência e sua utilização.

Como solução para corrosão, é necessário a remoção do concreto de cobrimento, a limpeza das barras de aço, aplicação do inibidor de corrosão, preparação da área de aplicação, recomposição do concreto com argamassa ou graute.

\subsection{Estudo de Caso 5}

Esse caso foi encontrado em duas paredes externas de um posto de saúde denominado PSF2 localizado na Rua Odilon Carvalho Braga,220 Viradouro SP, e nele encontra-se a presença de manchas brancas sobre a pintura, caracterizando-se um caso de eflorescência. Essa patologia, na maioria dos cenários, se desenvolve por grande quantidade de umidade no local, e sua formação se dá pela existência de sais solúveis nos materiais.

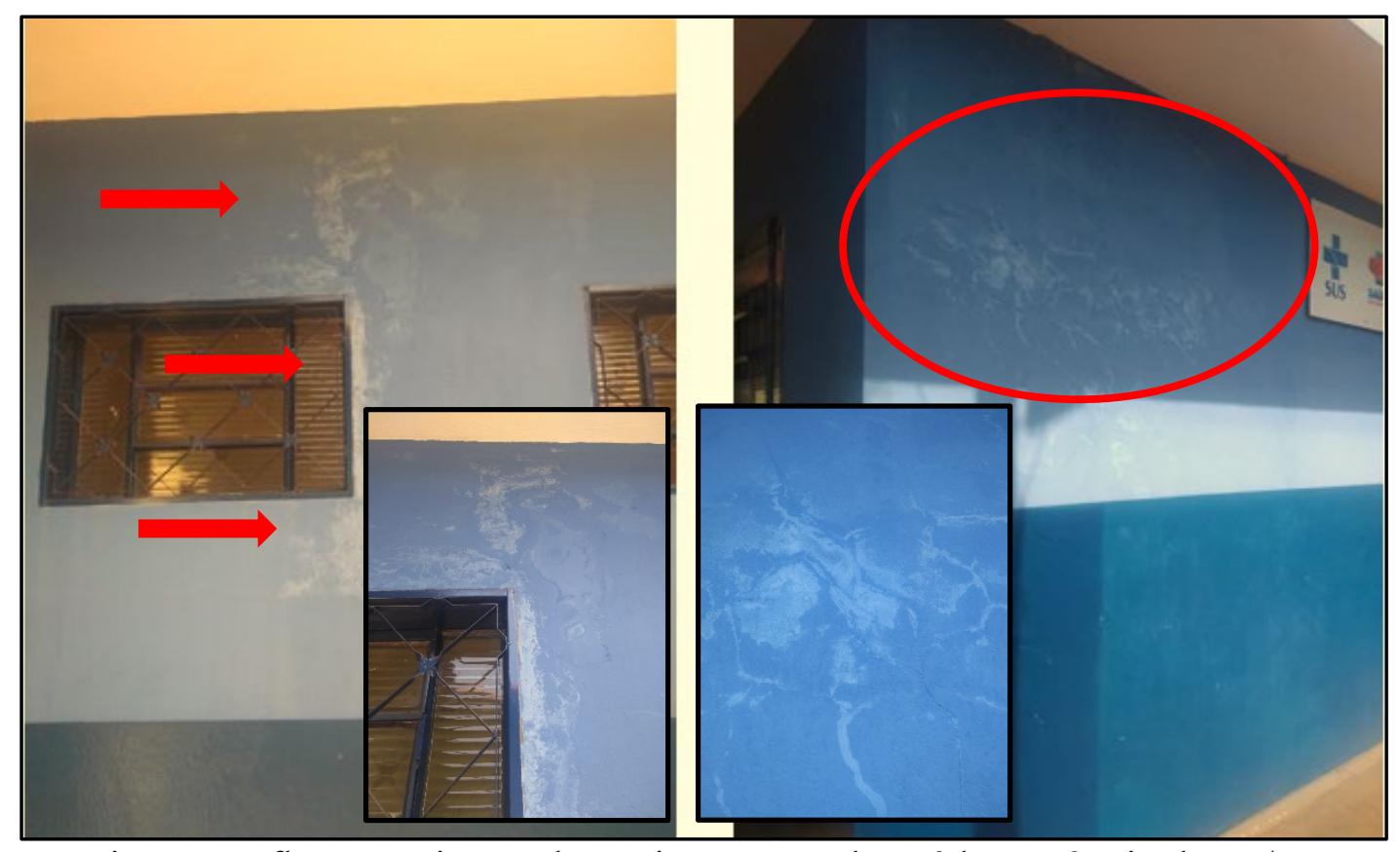

Figura 5. Eflorescência em alvenarias - Posto de Saúde PSF2 Viradouro/SP

As eflorescências podem ser superficiais, afetando somente o aspecto visual ou mais graves, quando atingem a parte estrutural do revestimento. $\mathrm{O}$ caso 5 exemplifica as superficiais, nota-se pela imagem que as manchas danificam a estética da edificação. Vale salientar que se trata de uma pintura recente, caso não sejam solucionadas, acarretarão em degradação do revestimento. 
Há três condições fundamentais para que apareçam eflorescências: quantidade de sais solúveis, presença de água e pressão hidrostática. A água (da chuva ou solo) é empurrada pela pressão hidrostática para fora do revestimento, carregando consigo os sais e, por evaporação, a água sai, deixando o depósito salino na superfície, o que ocasionam as manchas esbranquiçadas. Alguns outros fatores contribuem para essa patologia: excesso de água no processo de preparação das juntas; umidade constante; sais solúveis presentes no componente da alvenaria ou no amassamento da argamassa; utilização de cal não carbonatada.

De acordo com Menezes (2006) a existência de infiltração no imóvel representa grandes riscos à saúde, prejuízos financeiros tanto para consertar os danos, quanto a desvalorização do imóvel. Existem fatores que podem gerar aumento da intensidade e do número de patologias e problemas frequentes causados por umidade.

Como a principal causa é a presença de umidade, como terapia é necessário que elimine a infiltração. Primeiro passo é a verificação da mesma, caso a infiltração seja encontrada, deve-se eliminá-la. Logo após, lavagem do local com solução de ácido e impermeabilização com aplicação de $5 \%$ de hidrofugante na argamassa de proteção. Há também a possiblidade de aplicação de conversor de eflorescência, que reage com a cal livre presente nas argamassas e concretos e ao transformar em compostos endurecidos, elimina essa patologia, porém a mesma pode voltar, caso ocorra nova infiltração de água na área e por fim aplicação de impermeabilizante (hidrofugante).

\section{CONCLUSÃO}

O desenvolvimento do presente trabalho possibilitou o levantamento e a análise de manifestações patológicas recorrentes em edificações: trincas, fissuras, rachaduras, infiltrações, mofo, descolamento, corrosão de armaduras e eflorescências. Além disso, permitiu a realização de um estudo de caso visando a obtenção de dados mais consistentes sobre o tema em questão, tais como: causas, possíveis soluções e prevenções.

A gestão de prédios públicos exige de seus gestores, conhecimentos de ordem técnica, legal e administrativa. A segurança, a saúde e o bem estar dos usuários de prédios do Estado dependem de planejamento e eventualmente de ações rápidas de seus gestores no sentido de mantê-los em condições de funcionamento.

Ao examinar os prédios públicos selecionados no município de Viradouro - SP, comprovou-se o quão comumente é o aparecimento das manifestações patológicas abordadas no trabalho. A escolha por prédios públicos se deu pela falta de manutenção evidente, muitas vezes por descuido, falta de verbas ou contratação qualificada para solucionar as falhas.

Dada a importância do tema, o trabalho apontou a falta de manutenção preventiva e corretiva em prédios públicos, visto que alguns dos prédios analisados encontram-se em situação de abandono, como é o caso do Centro Comunitário e Velório, outros foram reformados recentemente e já apresentam manifestações patológicas, como é o caso do Posto de Saúde com eflorescências. Há ainda aqueles que entram em reformas por longos períodos, como a Prefeitura Municipal.

A grande quantidade de situações, muitas vezes interconectadas, evidenciam um quadro complexo de ser gerido. Para que se possa otimizar o esforço da gestão pública seria conveniente que fossem identificados e atacados aqueles problemas considerados mais críticos. A gestão da manutenção em prédios públicos, portanto, deve ser entendida como uma ferramenta através da qual se poderá alcançar a conservação de construções, materiais e equipamentos com poder transformador na cultura da comunidade. 


\section{REFERÊNCIAS}

ASSOCIAÇÃO BRASILEIRA DE ENGENHARIA E CONSULTORIA ESTRUTURAL (Pernambuco). Checklist para vistoria de edificações em concreto armado. Recife: Abece, 2005.

ASSOCIAÇÃO BRASILEIRA DE NORMAS TÉCNICAS. NBR 5674: Manutenção de edificações - Requisitos para o sistema de gestão de manutenção. Rio de Janeiro: Abnt, 2012.

ASSOCIAÇÃO BRASILEIRA DE NORMAS TÉCNICAS. NBR 6118: Projeto de estruturas de concreto - Procedimento. Rio de Janeiro: Abnt, 2003.

ASSOCIAÇÃO BRASILEIRA DE NORMAS TÉCNICAS. NBR 9575: Impermeabilização Seleção e projeto. Rio de Janeiro: Abnt, 2003.

ASSOCIAÇÃO BRASILEIRA DE NORMAS TÉCNICAS. NBR 15575-1: Edificações Habitacionais - Desempenho Parte 1: Requisitos gerais. Rio de Janeiro: Abnt, 2013.

ASSOCIAÇÃO BRASILEIRA DE NORMAS TÉCNICAS. NBR 13529: Revestimento de paredes e tetos de argamassas inorgânicas. Rio de Janeiro: Abnt, 2013.

ANDRADE, T.; SILVA, A. J. C. Patologia das Estruturas. In: ISAIA, Geraldo Cechella (Ed.). Concreto: ensino, pesquisa e realizações. São Paulo: IBRACON, 2005.

AMBRÓSIO, Thais da Silva. Patologia, tratamento e reforço de estruturas de concreto no metrô de São Paulo. Trabalho de conclusão de curso: São Paulo, 2004.

ARIVABENE, Antonio Cesar. Manifestações patológicas em Estruturas de Concreto Armado Estudo de Caso. 2015. 22 f. Monografia (Especialização) - Curso de Mba Gerenciamento de Obras, Tecnologia e Qualidade da Construção, Instituto de Pós-graduação - Ipog, Vitória, 2015.

BAÍA, Luciana Leone Maciel; SABBATINI, Fernando Henrique. Projeto e execução de revestimento de argamassa. 4. ed. São Paulo: O Nome da Rosa, 2008.

BARROS, M.M.B. et al. Tecnologia construtiva racionalizada para produção de revestimentos verticais. EPSUSP/ PCC. São Paulo, 1997. Disponível em: $<$ https:/www.passeidireto.com/arquivo/18909609/patologia-das-construcoes/7>

BAUER, Luiz Alfredo Falcão. Materiais de construção. 5. ed. Rio de Janeiro: Ltc - Livros Técnicos e Científicos, 2000. 488 p.

BAUER, R. J. F. Patologia em revestimentos de argamassa. In: SIMPÓSIO BRASILEIRO DE TECNOLOGIA DA ARGAMASSA, 2. 1997, Salvador. Anais... Salvador: ANTAC, 1997. p. 321362.

CAMPOMAR, M. C. Do uso de "estudo de caso" em pesquisas para dissertações e teses em administração. Revista de Administração, São Paulo, v.26, n. 3, p. 95-7, 1991.

CAPORRINO, Cristina Furlan. Patologia das anomalias em alvenarias e revestimentos argamassados. São Paulo: Pini, 2015. 
CARASEK, H. Argamassas. Materiais de Construção Civil e Princípios de Ciência e Engenharia de Materiais. Carasek, H. São Paulo, Ibracon, 2010. Disponível em: $<$ http://aquarius.ime.eb.br/ moniz/matconst2/argamassa_ibracon_cap26_apresentacao.pdf $>$, Acesso em 02 de agos. de 2021.

CINCOTTO, M.A. Patologia das argamassas de revestimento: análise e recomendações in: Tecnologia de Edificações. São Paulo: Ed. Pini. 1988.

COSTA, Vitor Coutinho de Camargo. Patologia em edificações ênfase em estruturas de concreto. 2009. 38 f. TCC (Graduação) - Curso de Engenharia Civil, Universidade Anhembi Morumbi, São Paulo, 2009.

COSTA, Pedro Laranja D'araujo. Manifestações patológicas no processo executivo de revestimentos de fachadas de edifícios. 2013. 81 f. TCC (Graduação) - Curso de Engenharia Civil, Universidade Federal do Rio de Janeiro, Rio de Janeiro, 2013.

GALVÃO, Dennis; JOSÉ, Jardeson; GOMES, Márcio. Manutenção em prédios públicos. 2017. 18 f. TCC (Graduação) - Curso de Engenharia Mecânica, Centro Universitário de Belo Horizonte, Belo Horizonte, 2017.

GODOY, Arilda Schmidt. Introdução à pesquisa qualitativa e suas possibilidades. RAE - Revista de Administração de Empresas, São Paulo, v. 35, n. 2, p. 57-63, 1995.

HELENE, Paulo Roberto Lago. Manual para reparo, reforço e proteção de estruturas de concreto. $2^{a}$ ed. São Paulo, Pini, 1992.

HELENE, Paulo Roberto Lago. Manual para Reparo, Reforço e Proteção de Estruturas de Concreto. São Paulo: Pini, 1997.

HELENE, Paulo Roberto Lago. Introdução da vida útil no projeto das estruturas de concreto. WORKSHOP SOBRE DURABILIDADE DAS CONSTRUÇÕES. São José dos Campos, 2001.

HELENE, Paulo R. Do Lago. Manual de reparo, proteção e reforço de estruturas de concreto. São Paulo, Red Rehabilitar, 2003.

JUNIOR, Clémenceau Chiabi Saliba. TRINCAS NAS EDIFICAÇÕES. Obras On Line, Minas Gerais, 2006.

LAPA, José Silva. Patologia, recuperação e reparo das estruturas de concreto. 2008. 56 f. TCC (Graduação) - Curso de Engenharia Civil, Universidade Federal de Minas Gerais, Belo Horizonte, 2008.

LIMA, Bruno Santos de. Principais manifestações patológicas em edificações residenciais multifamiliares. 2015. 66 f. TCC (Graduação) - Curso de Engenharia Civil, Centro de Tecnologia, Universidade Federal de Santa Maria, Santa Maria, 2015.

LOTTERMANN, Fabrício Nunes da. MANIFESTAÇÕES PATOLÓGICAS EM ESTRUTURAS DE CONCRETO: ESTUDO DE CASO. 2013. 66 f. TCC (Graduação) - Curso de Engenharia Civil, Universidade Regional do Noroeste do Estado do Rio Grande do Sul, Ijuí, 2013. 
MEDEIROS, Marcelo. Corrosão do concreto é causada por umidade e gases nocivos. 2008. Disponível em: <https://www.aecweb.com.br/cont/m/rev/corrosao-do-concreto-e-causada-porumidade-e-gases-nocivos_6412_0_1>. Acesso em: 03 dez. 2020.

MENEZES, R. R. et al. Sais solúveis e eflorescência em blocos cerâmicos e outros materiais de construção - revisão. Revista Cerâmica, v. 52, p. 37-49.2006.

NAKAMURA, J. Revestimento argamassado: Conheça as camadas que compõem um revestimento à base de argamassa e suas respectivas funções. Revista Equipe de obra. Agosto, 2013. Disponível em: <http://equipedeobra.pini.com.br/construcao-reforma/62/revestimentoargamassado-conheca-as-camadas-que-compoem-um-revestimento-292697-1.aspx>. Acesso em: 03 dez. 2020.

SOUZA, G. F. Eflorescências nas argamassas de revestimento. In: SIMPÓSIO BRASILEIRO DE TECNOLOGIA DA ARGAMASSA, 2. 1997, Salvador. Anais... Salvador: ANTAC, 1997. p. 341353.

THOMAZ, Ercio. Trincas em edifícios: Causas, prevenções e recuperação. São Paulo: Pini, 2014. 